\title{
In vitro lipolysis and lymphatic absorption of $n-3$ long-chain PUFA in the rat: influence of the molecular lipid species as carrier
}

\author{
Anthony Sehl ${ }^{1,2}$, Leslie Couëdelo ${ }^{1}$, Ikram Chamekh-Coelho ${ }^{1}$, Carole Vaysse ${ }^{1}$ and Maud Cansell ${ }^{2 *}$ \\ ${ }^{1}$ Nutrition Health and Lipid Biochemistry Department, ITERG, 33610 Canéjan, France \\ ${ }^{2}$ Chimie et Biologie des Membranes et des Nanoobjets (CBMN), Univ. Bordeaux, Bordeaux INP, UMR 5248, 33607 Pessac, \\ France \\ (Submitted 6 September 2018 - Final revision received 21 May 2019 - Accepted 17 June 2019)
}

\section{Abstract}

The aim of this work was to study the bioavailability of fatty acids (FA), focusing on $n-3$ long-chain (LC) PUFA, carried by different molecular lipid species, that is, phospholipids (PL) or TAG, with three formulations based on fish oils or marine PL, providing a similar $n$ - 3 LC PUFA amount. The digestive lipolysis was first assessed using an in vitro enzymatic model. Then, intestinal absorption and enterocyte metabolism were investigated in vivo, on male Wistar rats through lymph lipid analysis. The in vitro results showed that the release of $n-3$ LC PUFA from lipolysis was increased by $48 \%$ when FA were provided as PL rather than TAG. The in vivo results demonstrated that EPA and DHA from both TAG and PL were similarly absorbed and incorporated into lymph lipids. However, DHA was mainly distributed at the $s n-1 / 3$ positions of lymph TAG when provided as marine PL, whereas it was equally distributed at the three positions with marine TAG. On the whole, even if the molecular lipid species of $n$-3 LC PUFA did not greatly modify the in vivo digestion and absorption steps, it modulated the rearrangement of DHA on the glyceride positions of the lymph TAG, which may further impact the DHA metabolic fate and tissue accretion. Consequently, the present study has provided data which may be used to formulate lipid diets rich in DHA in the context of an insufficient consumption of $n$ - 3 PUFA in Western countries.

Key words: $n$-3 PUFA: TAG: Phospholipids: Bioavailability: Lymph

Numerous studies have demonstrated that $n-3$ PUFA, especially EPA $(20: 5 n-3)$ and DHA (22:6n-3), are associated with a reduced risk of developing several pathologies such as cardiovascular ${ }^{(1)}$, neurodegenerative ${ }^{(2)}$, inflammatory ${ }^{(3)}$ diseases and cancer $^{(4)}$. Indeed, EPA and DHA are directly implicated in lipid metabolism by lowering triacylglycerolaemia ${ }^{(5)}$ but they are also precursors of eicosanoids with strong anti-inflammatory properties ${ }^{(3,6)}$. Results from the latest French epidemiological study ${ }^{(7)}$ have shown that, even if the consumption of total lipids was in line with the recommendations (34\% of the total energy intake for 35-40\% recommended), EPA and DHA consumption was at least $32 \%$ lower than the French guidelines ( 117 and $169 \mathrm{mg} / \mathrm{d}$, respectively, for recommendations of $250 \mathrm{mg} / \mathrm{d}$ of each $n$-3 long-chain (LC) PUFA) ${ }^{(8,9)}$. In order to cover the $n-3$ LC PUFA physiological needs, increasing EPA and DHA intakes represents a major nutritional challenge. One of the strategies consists in improving their bioavailability, without changing the total lipid intake. Several studies have demonstrated that lipid bioavailability depends on physicochemical factors of the dietary intake ${ }^{(10-14)}$. Indeed, nowadays, EPA and DHA are essentially consumed as oily fish for food intake or as fish oil (mainly TAG or ethyl esters) in food supplements. In the case of food supplements, the interest for marine phospholipids (PL) has recently increased. However, the limited data concerning the impact of the molecular lipid species (TAG $v$. PL) of lipid intake on the $n-3$ LC PUFA fate leads to conflicting results. On the one hand, $n$-3 LC PUFA levels were increased in the liver and brain of rats fed EPA and DHA in the form of PL compared with $\mathrm{TAG}^{(15,16)}$. On the other hand, accretion of DHA in rat liver, plasma and kidney was significantly lower when it was provided as $\mathrm{PL}^{(17,18)}$. Human studies were even less conclusive. In a doubleblind, randomised, placebo-controlled, crossover study, a 4-week consumption of $600 \mathrm{mg}$ of $n$-3 LC PUFA in PL increased the $n-3$ LC PUFA levels in plasma and erythrocytes compared with the TAG form ${ }^{(19)}$. In contrast, no effect of the molecular species of the dietary lipids (TAG $v$. PL) was observed on $n$ - 3 LC PUFA levels in plasma and erythrocytes after 28 consecutive days of supplementation with $816 \mathrm{mg}$ EPA per $\mathrm{d}$ and $522 \mathrm{mg}$ DHA per $\mathrm{d}^{(20)}$. These contradictory results may account for different experimental designs, especially different EPA:DHA ratios, and prevent accurate comparison. Moreover, the impact of the molecular lipid species form was often studied by using fish oil for TAG and krill oil for PL. However, it is worth noting that krill oil only provides

Abbreviations 2-MG, 2-monoglycerides; CM, chylomicrons; FA, fatty acids; LC, long chain; PL, phospholipids; PLA 2 , phospholipase $\mathrm{A}_{2}$.

* Corresponding author: M. Cansell, fax +335 563703 36, email mcansell@enscbp.fr 
$40-60 \%$ of $n$ - 3 PUFA in the form of PL, while the remaining fraction originates from TAG and NEFA ${ }^{(21,22)}$. As a result, the role of PL as a lipid carrier on $n$-3 LC PUFA metabolic fate is not clearly established. To our knowledge, only one study provided n-3 PUFA only as TAG or as PL and showed a better lymphatic absorption of $n-3$ LC PUFA for rats fed PL $v$. TAG ${ }^{(23)}$. However, PL were structured in liposomes while TAG were provided as fish oil in bulk phase, so that the physical state of the two formulations was not comparable.

Thereby, the objective of the present study is to provide data on the digestibility and the intestinal absorption of $n-3$ LC PUFA according to their molecular lipid species, only in the bulk oily phase. Special attention was paid to ensure that the EPA:DHA ratio in the dietary lipid sources remained the same in order to ensure comparable results. $n$-3 LC PUFA esterified in TAG or PL were first subjected to an in vitro lipolysis in a titrimetric model. Intestinal absorption of $n-3$ LC PUFA was studied in vivo in a rat lymph duct fistula model. The lipid and fatty acid (FA) compositions of the lymph were analysed. It is worth noting that in vivo rodent models are considered as appropriate study models to assess oral compound bioavailability. They are often used in single-dose protocols or supplementation studies ${ }^{(11,12,14,23)}$. Indeed, similar physiological and physicochemical events, in particular those implying lipolytic enzymes, are described in both rodents and humans. Moreover, lymph analysis gives direct information on intestinal bioavailability, in contrast to blood, where the lipid composition may be contaminated by lipoproteins from liver metabolism. Thus, rat studies provide useful data to better understand the early stages of lipid digestion and investigate the intestinal bioavailability of FA of interest.

\section{Methods \\ Animals}

Male Wistar rats (8 weeks old, body weight: 300-350 g) were obtained from Elevage Janvier (Saint Genest sur l'Isle). All experiments were carried out in compliance with the ethic committee in Bordeaux and accepted by The French Ministry under no. 2017031014448864. Rats were treated in accordance with the European Communities Council Guidelines for the Care and Use of Laboratory Animals (2010/63/EU). All experiments conformed to the Guidelines for the Handling and Training of Laboratory Animals. Rats were housed four per cage $(480 \mathrm{~mm} \times 375 \mathrm{~mm} \times 210 \mathrm{~mm}$ ) for at least $7 \mathrm{~d}$ before the experiment in a controlled environment, at constant temperature $\left(22 \pm 1^{\circ} \mathrm{C}\right)$ and humidity $(60 \%)$ with free water and food access and a $12 \mathrm{~h}$ light-12 h dark cycle.

\section{Experimental design}

At $24 \mathrm{~h}$ before surgery, rats were fed a fat-free diet (SAFE) with free access to water. Each rat was placed under anaesthesia by an intra-peritoneal injection of a ketamine-xylazine mixture (100/10 mg/kg, respectively; Axience). A polyethylene catheter $(0.95 \mathrm{~mm} \times 15 \mathrm{~cm}$; Biotrol) was inserted into the main mesenteric lymph duct as described by Bollman et al. $^{(24)}$ and Couëdelo et $a l .{ }^{(12)}$. Immediately after surgery, rats were randomly assigned to one of the three experimental groups (six rats/group), corresponding to one of the three $n$ - 3 LC PUFA-enriched formulations ( $\mathrm{TAG}_{n-3}, \mathrm{TAG}_{n-3}+\mathrm{PL}_{\mathrm{veg}}$, and $\mathrm{TAG}_{\mathrm{veg}}+\mathrm{PL}_{n-3}$ ). A volume, equivalent to $1 \mathrm{~g}$ of formulation, was orally administrated by gavage, providing, respectively, 8.6 and $22.3 \mathrm{mg}$ of EPA and DHA per rat. Each rat was then placed in an individual restraining cage (rat compartment $228 \mathrm{~mm} \times 89 \mathrm{~mm}$ ), in a warm environment with freely available water. After gavage, lymph was collected during $6 \mathrm{~h}$ in a collection tube stored in ice. To prevent pain, rats received an intra-peritoneal injection of buprenorphine $(0.02 \mathrm{mg} / \mathrm{kg}$; Axience) $1 \mathrm{~h}$ before and $2 \mathrm{~h}$ after surgery. At $6 \mathrm{~h}$ post-intubation, rats were euthanised by an intra-peritoneal injection of sodium pentobarbital (Axience) and lidocaine (Ceva).

\section{Lipid formulations}

The lipid formulations were prepared at room temperature under nitrogen in order to prevent PUFA oxidation. Three marine formulations were designed to provide a similar amount of FA, but differed by the chemical structure of lipids. More precisely, EPA and DHA were exclusively esterified either on TAG or on PL molecules (Table 1).

Marine PL were extracted from Lecimarin F50 (Novastell) by solvent fractionation using cold acetone. Briefly, $1 \mathrm{ml}$ of chloroform-methanol (2:1, v/v) was added to $1 \mathrm{~g}$ of marine lecithin and maintained at room temperature until complete solubilisation. After addition of $20 \mathrm{ml}$ of cold acetone $\left(-20^{\circ} \mathrm{C}\right)$, the sample was homogenised and then centrifuged (1050 g, $5 \mathrm{~min}, 4^{\circ} \mathrm{C}$; Sorvall ST-40R, Thermo Fisher Scientific). The supernatant, containing the neutral lipids, was removed and the pellet, containing the polar lipids, was extracted twice with cold acetone and stored at $-20^{\circ} \mathrm{C}$.

The formulation providing EPA and DHA only esterified in PL $\left(\mathrm{TAG}_{\mathrm{veg}}+\mathrm{PL}_{n-3}\right.$ ) was prepared by solubilising marine PL (13 wt.\%) to a mixture of vegetable oils (flaxseed-copra-grapeseed-palm-oleic sunflower oils; 1:6:6:30:57, by weight). The formulation including EPA and DHA only on TAG ( TAG $_{n-3}$ ) was obtained by blending two fish oils (Omegavie 1812 TG and Omegavie Tuna oil $25 \%$ DHA; $1: 10, \mathrm{w} / \mathrm{w}$; Polaris) to 11 wt.\% of blended vegetable oils (flaxseed-copra-grapeseedpalm-oleic sunflower oils; 1:6:6:31:56, by weight). In order to distinguish the role of PL, acting either as emulsifier or as FA carrier, a third formulation ( $\mathrm{TAG}_{n-3}+\mathrm{PL}_{\mathrm{veg}}$ ) was prepared including vegetable PL (without $n$ - 3 LC PUFA contribution). More precisely, $11 \mathrm{wt} . \%$ of the marine oil and $10 \mathrm{wt} . \%$ of soya lecithin (Nat\&Form) were added to a mixture of vegetable oils (copra, palm and oleic sunflower oils; 6:30:63, by weight).

Phospholipid classes of marine polar lipid extract and of soya lecithin were characterised by proton NMR $\left({ }^{1} \mathrm{H}\right.$ NMR $)$ according to Cansell et al. ${ }^{(25)}$ (Table 1). The glyceride structure of the marine oil mixture and of the marine PL was enzymatically determined according to the methods described below. In the marine TAG (oil mixture), EPA was mainly esterified in the $s n-1 / 3$ positions of marine TAG ( $26 \%$ in the $s n-2$ position), whereas DHA was mainly located in the $s n-2$ position (50\%). In marine PL, both EPA and DHA were essentially distributed in the $s n-2$ position $(>74 \%$ ) (see online Supplementary material S1). 
Table 1. Fatty acid and phospholipid (PL) compositions of the three experimental lipid formulations

\begin{tabular}{|c|c|c|c|}
\hline & $\mathrm{TAG}_{n-3}$ & $\mathrm{TAG}_{n-3}+\mathrm{PL}_{\mathrm{veg}}$ & $\mathrm{TAG}_{\mathrm{veg}}+\mathrm{PL}_{n-3}$ \\
\hline \multicolumn{4}{|c|}{ Fatty acid composition ( $\mathrm{g} / 100 \mathrm{~g}$ total fatty acids) } \\
\hline$\Sigma$ SFA & 32.6 & 31.4 & 31.0 \\
\hline $16: 0$ & $15 \cdot 9$ & $15 \cdot 4$ & $15 \cdot 4$ \\
\hline $18: 0$ & 3.5 & 3.4 & $3 \cdot 3$ \\
\hline$\Sigma$ MUFA & $55 \cdot 0$ & $57 \cdot 0$ & $56 \cdot 7$ \\
\hline $18: 1 n-9$ & $52 \cdot 8$ & 54.6 & $55 \cdot 1$ \\
\hline$\Sigma$ PUFA & $12 \cdot 4$ & $11 \cdot 6$ & $12 \cdot 3$ \\
\hline$\Sigma n-6$ PUFA & 8.6 & $7 \cdot 7$ & $8 \cdot 7$ \\
\hline $18: 2 n-6$ & $8 \cdot 2$ & $7 \cdot 2$ & $8 \cdot 4$ \\
\hline $20: 4 n-6$ & $0 \cdot 2$ & 0.2 & 0.0 \\
\hline$\Sigma n-3$ PUFA & $3 \cdot 8$ & 3.9 & 3.4 \\
\hline $18: 3 n-3$ & 0.7 & 0.4 & 0.7 \\
\hline $20: 5 n-3$ & 0.8 & 0.9 & 0.7 \\
\hline $22: 6 n-3$ & $2 \cdot 0$ & $2 \cdot 2$ & 1.9 \\
\hline$n-6: n-3$ & $2 \cdot 3$ & $2 \cdot 0$ & $2 \cdot 6$ \\
\hline \multicolumn{4}{|c|}{ PL composition (g/100 g total PL) } \\
\hline Phosphatidylcholine & & $31 \cdot 7$ & $73 \cdot 8$ \\
\hline Phosphatidylinositol & & $29 \cdot 3$ & 3.5 \\
\hline Phosphatidylethanolamine & & $29 \cdot 6$ & $5 \cdot 2$ \\
\hline Phosphatidylserine & & 5.4 & - \\
\hline Phosphatidic acid & & $4 \cdot 0$ & 1.2 \\
\hline Sphingomyelin & & - & $2 \cdot 9$ \\
\hline Lysophosphatidylcholine & & - & $9 \cdot 2$ \\
\hline
\end{tabular}

LC, long-chain; $T_{A G}$, oil phase with $n-3$ LC PUFA esterified in TAG; TAG ${ }_{n-3}+\mathrm{PL}_{\text {veg }}$ oil and soya lecithin mix with $n-3$ LC PUFA esterified in TAG; $T A G_{\text {veg }}+P L_{n-3}$, oil and marine PL mix with $n-3$ LC PUFA esterified in PL.

\section{Lipid analysis}

The total lipids were extracted from the lymph according to the procedure described by Folch et $a l^{(26)}$. PL and TAG fractions from the lipid extract were separated by TLC (glass plates $20 \times 20 \mathrm{~cm}$ pre-coated with silica gel $60 \mathrm{H}$ ) using a solvent mixture composed of hexane-diethyl ether-formic acid (75:35:1, by vol.). After vaporisation of 2,7-dichlorofluorescein (Sigma-Aldrich) and visualisation under UV light, the spots corresponding to PL and TAG were extracted from the silica gel by the addition of $2.5 \mathrm{ml}$ of chloroform-methanol (2:1, v/v). After homogenisation and centrifugation of the scraped fractions $\left(1050 \mathrm{~g}, 5 \mathrm{~min}, 20^{\circ} \mathrm{C}\right)$, the organic phase containing lipids was collected. The extraction step was repeated by the addition of distilled water $(100 \mu \mathrm{l})$ and chloroform-methanol $2 \mathrm{ml}(2: 1, \mathrm{v} / \mathrm{v})$ to the silica gel phase. Lipid extraction from the silica gel was ended by the addition of $2 \mathrm{ml}$ of methanol to the silica gel phase, homogenisation and centrifugation. The overall organic phases were pooled and dried under nitrogen. Finally, 2,7-dichlorofluorescein was removed using $0.4 \mathrm{ml}$ of a $\mathrm{KCl}$ solution $(0.8 \%$ in distilled water, $\mathrm{w} / \mathrm{v})$ and $2 \mathrm{ml}$ of chloroformmethanol $(2: 1, \mathrm{v} / \mathrm{v})$. The organic phase was washed twice by the addition of $0.8 \mathrm{ml}$ of a mixture of chloroform-methanol- $\mathrm{KCl}$ $0 \cdot 8 \%$ in distilled water (15:240:235, by vol.). Samples were stored at $-20^{\circ} \mathrm{C}$ until analysis.

The FA composition of the lipid formulations, the samples from the in vitro lipolysis experiments and those collected from the lymph, that is, total lipids, TAG and PL fractions, were submitted to the trans-methylation procedure adapted from CastroGomez ${ }^{(27,28)}$. The resulting fatty acid methyl esters were analysed by GC analysis (TRACE GC, Thermo Fisher Scientific) equipped with a flame ionisation detector and a split injector. A fused-silica capillary column $(\mathrm{BPX} 70,60 \mathrm{~m} \times 0.25 \mathrm{~mm}$ internal diameter,
$0.25 \mu \mathrm{m}$ film; SGE) was used with hydrogen as a carrier gas (inlet pressure: $120 \mathrm{kPa}$ ). The split ratio was 1:33. The column temperature program was as follows: from $160^{\circ} \mathrm{C}$, the temperature increased to $180^{\circ} \mathrm{C}$ at $1.3^{\circ} \mathrm{C} / \mathrm{min}$ and was maintained for $65 \mathrm{~min}$ before increasing at $25^{\circ} \mathrm{C} / \mathrm{min}$ to $230^{\circ} \mathrm{C}$, temperature that was maintained for $15 \mathrm{~min}$. The injector and detector were maintained at $250^{\circ} \mathrm{C}$ and $280^{\circ} \mathrm{C}$, respectively. Gas chromatographic peaks were integrated using Chromquest software (Thermofinnigan). Fatty acids were quantified using an internal standard $(1 \mathrm{mg} / \mathrm{ml}$ in chloroform-methanol $(2: 1, \mathrm{v} / \mathrm{v}))$ added at $10 \%$ of the lipid weight before the trans-methylation procedure. NEFA 17 : 0 (heptadecanoic acid; Nu-Chek Prep) was used as an internal standard for the in vitro lipolysis study. TAG 17 : 0 (1,2,3triheptadecanoyl-sn-glycerol; Nu-Chek Prep) and PC 17 : 0 (1,2diheptadecanoyl-sn-glycero-3-phosphatidylcholine; Avanti Polar Lipids) were used for TAG and PL quantification of the lymph samples, respectively.

The proportion of FA esterified in the $s n-2$ position of lymph TAG was determined using the regiospecificity of lipase. Lymph TAG (3 mg) were mixed with $1 \mathrm{ml}$ of lipase B Candida antartica (>2000 U/g; $1 \mathrm{U}=1 \mu \mathrm{Eq} \mathrm{FA} / \mathrm{h}$; Sigma-Aldrich) in ethanol solution $(4 \mathrm{mg} / \mathrm{ml}, \mathrm{w} / \mathrm{v})$ and placed under stirring, at $30^{\circ} \mathrm{C}$ for $3 \mathrm{~h}$. Lipids were extracted six times by $10 \mathrm{ml}$ of diethyl ether. Hydrolysis products were separated by TLC using a solvent mixture composed of hexane-diethyl ether-acetic acid (70:30:1, by vol.). After vaporisation of 2,7-dichlorofluorescein and visualisation under UV light, the spots corresponding to the 2-monoacylglycerols (2-MG) were scraped off and transferred into a glass tube for their trans-methylation. The proportion of FA esterified in the $s n-2$ position of TAG was calculated by considering the proportions of each FA from 2-MG compared with those from the three positions of the TAG, with the following equation:

$\% \mathrm{FA}$ in $s n-2 \mathrm{TAG}=(\% \mathrm{FA}$ in $2-\mathrm{MG} \times 100) /(\% \mathrm{FA}$ in $\mathrm{TAG} \times 3)$.

The glyceride structure of lymph PL was achieved by phospholipase $\mathrm{A}_{2}\left(\mathrm{PLA}_{2}\right)$ hydrolysis according to the Wolff et al. ${ }^{(29)}$ method, using $\mathrm{PLA}_{2}$ from bee venom $(600-2400 \mathrm{U} / \mathrm{g} ; 1 \mathrm{U}=1$ $\mu \mathrm{Eq} \mathrm{FA} / \mathrm{h}$; Sigma-Aldrich). Briefly, $150 \mu \mathrm{l}$ of a PLA 2 solution $\left(1 \mathrm{mg} / \mathrm{ml} ; 3 \mathrm{~mm} \mathrm{CaCl}_{2}\right.$ ) was added to $2 \mathrm{mg}$ of extracted lymph PL and $1 \mathrm{ml}$ of diethyl ether. Samples were incubated under stirring, at $30^{\circ} \mathrm{C}$ for $1 \mathrm{~h}$. The reaction was stopped by solvent evaporation under nitrogen. Hydrolysis products were separated by TLC using a solvent mixture of chloroform-methanol-distillated water (65:25:4, by vol.). NEFA were scraped off and transferred into a glass tube for methylation. The proportion of FA esterified in the $s n-2$ position of PL was calculated by considering the proportions of each FA released as NEFA compared with those from the two positions of the PL, with the following equation:

$$
\% \mathrm{FA} \text { in } s n-2 \mathrm{PL}=(\% \mathrm{FA} \text { in NEFA } \times 100) /(\% \mathrm{FA} \text { in } \mathrm{PL} \times 2) .
$$

\section{In vitro intestinal lipolysis of lipid formulations}

The enzymatic lipolysis of the lipid formulations was assessed using an in vitro digestion model that mimics the physiological 
conditions of the intestinal lumen according to Carrière $e t a l{ }^{(30)}$ and Minekus et al. ${ }^{(31)}$ with slight modifications. The lipolysis was initiated by $5 \mathrm{ml}$ of a $25 \%$ lipid emulsion stabilised by $1.4 \%(\mathrm{w} / \mathrm{v})$ of methyl cellulose (Sigma-Aldrich) and dispersed in $15 \mathrm{ml}$ of an assay solution containing $0.6 \%(\mathrm{w} / \mathrm{v})$ of methyl cellulose, $150 \mathrm{~mm} \mathrm{NaCl}$ (Thermo Fisher Scientific), $1.4 \mathrm{~mm} \mathrm{CaCl}_{2}$ (SigmaAldrich) and $20 \mathrm{~mm}$ sodium deoxycholate (Sigma-Aldrich). This mixture was stirred in a temperature-controlled reaction vessel at $37^{\circ} \mathrm{C}$ and the $\mathrm{pH}$ was adjusted to $7 \cdot 5$. The lipolysis was initiated by adding $1 \mathrm{ml}$ of porcine pancreas extract solution $(6.7 \mathrm{mg} / \mathrm{ml}$ in distilled water, $\mathrm{pH} 7.5$; Sigma-Aldrich) to the reaction vessel. The $\mathrm{pH}$ was kept constant at $7 \cdot 5$ for 60 min with $0 \cdot 1 \mathrm{M}$ $\mathrm{NaOH}$ (Chem-Lab) automatically controlled by a pH-stat device (pHstat Titrando, Metler Toledo). Samples (0.5 ml) were collected at times ranging from 0 to $60 \mathrm{~min}$ for lipid extraction and analysis. Lipid extraction was immediately performed by mixing each sample vigorously $(0.5 \mathrm{ml})$ with $200 \mu \mathrm{HCl}$ $(0 \cdot 1 \mathrm{~m}$; Thermo Fisher Scientific) and $5 \mathrm{ml}$ chloroform-methanol $(2: 1, v / v)$ in a glass tube. After phase separation, the upper aqueous phase was removed and the lower phase containing the total lipids was dried under nitrogen, dissolved in $3 \mathrm{ml}$ chloroformmethanol $(2: 1, \mathrm{v} / \mathrm{v})$, and stored at $-20^{\circ} \mathrm{C}$ until analysis. NEFA, from TAG and PL lipolysis, were isolated from other lipid fractions by TLC (glass plates $20 \times 20 \mathrm{~cm}$ pre-coated with silica gel $60 \mathrm{H}$ (Merck KGaA)) using a solvent mixture composed of hexane-diethyl ether-acetic acid (80:20:1, by vol.). Spots were visualised under UV light after vaporisation of 2,7-dichlorofluorescein in ethanol solution $(0 \cdot 2 \%, \mathrm{w} / \mathrm{v})$. NEFA were scraped off and transferred into a glass tube for methylation and GC analysis. At each time point of the kinetics $(0,5,10,15,30$ and $60 \mathrm{~min})$, the hydrolysis level (\% NEFA/total FA) was calculated. A deprived $n$-3 LC PUFA formulation composed of $10 \mathrm{wt} . \%$ of soya lecithin dissolved in a vegetable oil mixture (copra-palm-oleic sunflower oil; 6:30:63, by weight; $\mathrm{TAG}_{\mathrm{veg}}+\mathrm{PL}_{\mathrm{veg}}$ ) was also assessed as a control (see online Supplementary material S2). Lipolysis experiments were performed in triplicate, for each formulation, that is, $\mathrm{TAG}_{n-3}, \mathrm{TAG}_{n-3}+\mathrm{PL}_{\mathrm{veg}}$ and $\mathrm{TAG}_{\mathrm{veg}}+\mathrm{PL}_{n-3}$.

\section{Characterisation of lymph chylomicrons}

The size of the lymph chylomicrons (CM) was measured for each rat group by dynamic light scattering using Vasco ${ }^{\mathrm{TM}}$ (Cordouan Technologies). Lymph samples were firstly diluted in $\mathrm{NaCl}$ solution in water $(0.9 \%, \mathrm{w} / \mathrm{v})$. Experiments were performed considering a water refractive index of 1.331 and a viscosity of $0.888 \mathrm{cP}$. The real part and the imaginary part of particles were fixed at 1.47 and $0 \cdot 01$, respectively.

\section{Statistical analysis}

Data were expressed as means and standard deviations. Intergroup comparisons were made on the basis of their respective mean. For the in vitro lipolysis experiment ( $n 3$ ), multiple comparisons were analysed using a two-way ANOVA with two independent factors (lipid formulation and time of lipolysis) followed by a Bonferroni post hoc test, using GraphPad Prism version 7. Data issued from the in vivo intestinal absorption experiment ( $n$ 6) were compared by a one-way ANOVA test followed by a Tukey post hoc test, using $\mathrm{R}$ version 3.5.1
(Rcommander package). $P$ values lower than 0.05 were considered to be statistically significant.

\section{Results}

In vitro digestion of $\mathrm{n}-3$ long-chain PUFA is modulated by their molecular lipid species of intake

Marine formulations $\left(\mathrm{TAG}_{n-3}, \mathrm{TAG}_{n-3}+\mathrm{PL}_{\mathrm{veg}}, \mathrm{TAG}_{\mathrm{veg}}+\mathrm{PL}_{n-3}\right.$ ) were subjected to in vitro lipolysis in a one-step static digestion model, with a focus on the duodenal lipolysis (Fig. 1). Results revealed that all lipid formulations were well hydrolysed during the time course of the lipolysis but to a different extent according to the formulation used ( $P_{\text {time }}<0.001 ; P_{\text {lipids }}=0.05$ and $P_{\text {interaction }}<0.001 ;$ two-way ANOVA test). At the end of the lipolysis kinetics ( $60 \mathrm{~min}$ ), the presence of soya lecithin in the marine formulation $\left(\mathrm{TAG}_{n-3}+\mathrm{PL}_{\mathrm{veg}}\right.$ ) tended to inhibit the total lipolysis compared with $\mathrm{TAG}_{n-3}$ (lipolysis level of 21.3 (SD 4.7 ) \% and 14.5 (SD 1.5) \%, for $\mathrm{TAG}_{n-3}$ and $\mathrm{TAG}_{n-3}+\mathrm{PL}_{\mathrm{veg}}$, respectively). The lipolysis of $\mathrm{TAG}_{n-3}+\mathrm{PL}_{\mathrm{veg}}$ formulation was decreased by $47 \%$ when compared with the formulation free of $n$-3 LC PUFA (lipolysis level of 14.5 (SD 1.5) \% and 27.3 (SD 1.9$) \%$ for $\mathrm{TAG}_{n-3}+\mathrm{PL}_{\mathrm{veg}}$ and $\mathrm{TAG}_{\mathrm{veg}}+\mathrm{PL}_{\mathrm{veg}}$, respectively; $P<0.05)$. When $n-3$ LC PUFA were esterified in marine PL $\left(\mathrm{TAG}_{\mathrm{veg}}+\mathrm{PL}_{n-3}\right.$ ), the lipolysis seemed to be slower at the beginning of the kinetics compared with the control curve $\left(\mathrm{TAG}_{\mathrm{veg}}+\mathrm{PL}_{\mathrm{veg}}\right.$ ); however at $60 \mathrm{~min}$, the lipolysis levels were not statistically different (21.5 (SD 4.3)\% and 27.3 (SD 1.9)\% for $\mathrm{TAG}_{\mathrm{veg}}+\mathrm{PL}_{n-3}$ and $\mathrm{TAG}_{\mathrm{veg}}+\mathrm{PL}_{\mathrm{veg}}$, respectively).

Influence of the molecular lipid species of the dietary lipids on the intestinal absorption of n-3 long-chain PUFA

At $6 \mathrm{~h}$ after lipid ingestion, no adverse effect was observed consecutive to lipid formulation intubation. The total FA concentration in the rat lymph was similar for the three marine formulations (Table 2). The proportions of EPA and DHA in lymph total FA did not show statistical differences between all groups. Lymph TAG and PL were separated and their FA compositions were analysed separately (Table 3 ). The relative proportions of lymph TAG and PL were similar regardless of the molecular $n$-3 LC PUFA carrier ( $P>0 \cdot 05)$. Thereby, TAG was the major lipid fraction ( $71 \%$ of total FA) while PL only represented $7 \%$ of total FA. Lymph TAG presented a similar FA profile between the three groups $(P>0 \cdot 05)$. SFA and MUFA were the two major FA classes, and PUFA were mainly represented by $n-6$ PUFA. Considering n-3 PUFA, EPA and DHA levels in lymph TAG were similar in the three groups. In lymph PL, the incorporation of $n-3$ LC PUFA and specifically EPA was quite low. DHA levels tended to be higher in the $\mathrm{TAG}_{\mathrm{veg}}+\mathrm{PL}_{n-3}$ than in $\mathrm{TAG}_{n-3}$ and $\mathrm{TAG}_{n-3}+\mathrm{PL}_{\mathrm{veg}}(P=0 \cdot 10)$. The proportions of the main FA esterified in the $s n-2$ position of lymph lipids were defined (Table 4). We noted that SFA, MUFA and PUFA were equally distributed in the three positions of lymph TAG for all groups. In lymph PL, SFA were mostly esterified in the $s n$ - 1 position and PUFA in the $s n-2$, irrespective of the groups. Considering $n-3$ LC PUFA, EPA and DHA were mainly located in the $s n-2$ position of lymph PL regardless the molecular FA carrier (TAG $v$. PL). DHA was equally esterified in the three positions of lymph TAG when provided as marine TAG 


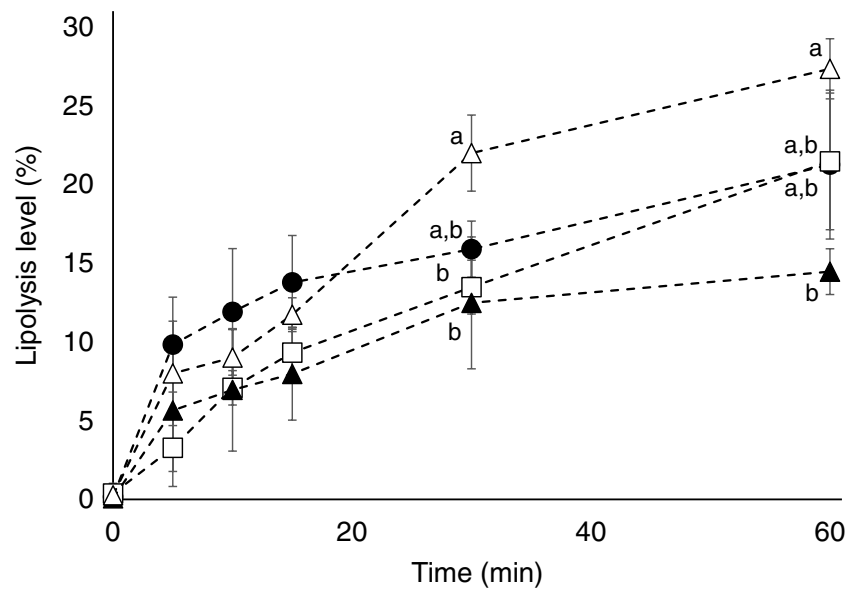

Fig. 1. Effect of lipid formulation on lipolysis levels using an in vitro digestion model. $\mathrm{TAG}_{n-3}(\bullet), \mathrm{TAG}_{n-3}+\mathrm{PL}_{\text {veg }}(\mathbf{(}), \mathrm{TAG}_{\text {veg }}+\mathrm{PL}_{n-3}(\square)$ and $\mathrm{TAG}_{\text {veg }}+\mathrm{PL}_{\text {veg }}(\Delta)$. Lipolysis levels are expressed as \% NEFA $v$. total acyl chains in the residual TAG, diacylglycerols, monoacylglycerols and NEFA. Values are means with standard deviations $(n 3)$. ${ }^{\text {a,b }}$ Values with unlike letters for the same time are significantly different $(P<0.05$; two-way ANOVA followed by Bonferroni post hoc test).

( TAG $_{n-3}$ and TAG $_{n-3}+\mathrm{PL}_{\mathrm{veg}}$ ), whereas it was mainly located in the $s n-1 / 3$ positions when ingested as marine $\mathrm{PL}\left(\mathrm{TAG}_{\mathrm{veg}}+\mathrm{PL}_{n-3}\right.$; $P<0 \cdot 001)$. More precisely, the intake of marine PL decreased by $46 \%$ the proportion of DHA esterified in the $s n-2$ position of lymph TAG. However, EPA was mainly inserted in the $s n-1 / 3$ positions of lymph TAG in all groups.

\section{Characterisation of lymph chylomicrons}

Lymph CM were analysed in terms of particle size. Data revealed that the mean diameter of CM were comparable between the three groups (223 (SD 28), 248 (SD 46) and 227 (SD 47) nm for $\mathrm{TAG}_{n-3}, \mathrm{TAG}_{n-3}+\mathrm{PL}_{\mathrm{veg}}$ and $\mathrm{TAG}_{\mathrm{veg}}+\mathrm{PL}_{n-3}$, respectively).

\section{Discussion}

The present study aims at evaluating the impact of the molecular lipid species of dietary $n-3$ LC PUFA on (i) their in vitro digestibility and (ii) their intestinal bioavailability, in rats fed marine TAG or PL. Only few studies tried to couple in vitro lipid hydrolysis with in vivo absorption and they dealt with plant lipids ${ }^{(11,12)}$. A recent study used marine lipids ${ }^{(32)}$. However, the formulations did not have a similar EPA:DHA ratio and did not allow comparison of PL as $n-3$ carrier or as emulsifier. In our work, lipid formulations were designed to provide a similar amount of EPA and DHA, esterified exclusively either in TAG or in PL molecules. Because PL display surfactant properties that may influence lipid digestibility and absorption, a formulation containing soya lecithin instead of marine PL $\left(\mathrm{TAG}_{n-3}+\mathrm{PL}_{\mathrm{veg}}\right.$ ) was also assessed. Results showed that even if the in vitro lipolysis level was dependent on the type of the formulation used, EPA and DHA were similarly absorbed, in vivo, regardless of the lipid carrier. However, they were differently distributed in lymph lipid fractions. Specifically, when provided as marine PL, n-3 LC PUFA tended to be better incorporated in lymph PL and DHA was more externalised in the glycerol backbone of lymph TAG. To our knowledge, this is the first study analysing the molecular structure of lymph lipid fractions using marine TAG and PL as dietary n-3 LC PUFA carriers.

Gastro-intestinal digestion can be considered as a limiting step of bioavailability. This is because dietary lipids first have to be hydrolysed in the gastro-intestinal tract, before being absorbed by the intestinal brush border. In our study, we did not perform a gastric phase before the duodenal phase, which could be a limitation. However (1) duodenal lipolysis represents nearly $70 \%$ of total lipolysis ${ }^{(33)}$ and (2) the efficiency of the intestinal lipolysis is not called into question by the gastric phase. Our data confirmed that lipolysis extent depended on the affinity of pancreatic lipase towards the lipid species. The presence of $n-3$ LC PUFA esterified in marine TAG $\left(\mathrm{TAG}_{n-3}+\mathrm{PL}_{\mathrm{veg}} v\right.$. $\mathrm{TAG}_{\mathrm{veg}}+\mathrm{PL}_{\mathrm{veg}}$ ) dramatically impaired the lipolysis rate, due to the molecular structure of EPA and DHA which led to a steric hindrance effect in in vitro studies ${ }^{(34,35)}$. In agreement with other studies ${ }^{(12,36)}$, we observed an inhibitory effect of soya PL $\left(\mathrm{TAG}_{n-3} v \cdot \mathrm{TAG}_{n-3}+\mathrm{PL}_{\mathrm{veg}}\right.$ ). This could be interpreted as an impediment of the binding of pancreatic lipase/co-lipase at the oil-water interface, decreasing TAG availability for hydrolysis ${ }^{(37,38)}$. Moreover, the PL nature influenced the lipid hydrolysis level $\left(\mathrm{TAG}_{\mathrm{veg}}+\mathrm{PL}_{\mathrm{veg}} v \cdot \mathrm{TAG}_{\mathrm{veg}}+\mathrm{PL}_{n-3}\right.$ ). In our experiment, the porcine pancreas extract contained $\mathrm{PLA}_{2}$. It is well known that $\mathrm{PLA}_{2}$ activity is modulated by the nature of the polar head group of PL and to a lesser extent by the FA nature, that is, chain length or unsaturation degree ${ }^{(39,40)}$. Several studies using liposomes ${ }^{(41,42)}$ and emulsion droplets ${ }^{(43)}$ showed that PLA 2 would preferentially bond to anionic PL rather than zwitterionic PL. Thus, in our study, a part of the decreased lipolysis observed with $\mathrm{TAG}_{\mathrm{veg}}+\mathrm{PL}_{n-3}$ formulation could be attributed to the PL composition ( $5 \%$ of anionic $\mathrm{PL}$ in $\mathrm{PL}_{n-3} v .39 \%$ in $\mathrm{PL}_{\mathrm{veg}}$ ).

The products generated by the lipid hydrolysis (NEFA, 2-MG, and lysophospholipids) are micellised by biliary salts before being absorbed through the intestinal brush border. In the enterocytes, the lipolysis products are re-synthesised in TAG and PL, compacted into CM to be released into the lymph compartment before reaching the bloodstream. In our experiment, the $\mathrm{CM}$ diameter was similar, whatever the molecular carriers used, suggesting that the structural properties of CM were impacted neither by the presence of PL in the formulation nor by the molecular $n$-3 LC PUFA carrier used, nor by the variations of lipolysis rates observed in vitro. This finding is in accordance with a previous study demonstrating that the lipid composition of CM did not differ in rats fed fish oil or marine $\mathrm{PL}^{(23)}$.

In all experimental groups, the FA quantification and FA profile of total lymph lipids were similar, suggesting that, under our test conditions, the digestion and the intestinal absorption of $n-3$ LC PUFA were not modulated by the molecular $n$ - 3 LC PUFA carrier $\left(\mathrm{TAG}_{n-3} v . \mathrm{PL}_{n-3}\right.$ ). Moreover, lymph lipids were mainly composed of PL and TAG and the incorporation of EPA and DHA in lymph lipid fractions occurred independently of the molecular lipid species used (i.e. TAG, PL, lysophospholipids, NEFA) ${ }^{(23,42-44)}$. Indeed, the FA profile of lymph TAG revealed similar $n-3$ PUFA levels between the three groups, suggesting that EPA and DHA were incorporated in lymph TAG regardless of the molecular FA carrier. However, in lymph PL, DHA levels tended to increase when provided as marine PL $\left(\mathrm{TAG}_{\mathrm{veg}}+\mathrm{PL}_{n-3}\right)$ compared with the TAG 
Table 2. Effect of the molecular carrier form of $n-3$ long-chain (LC) PUFA on fatty acid composition ( $\mathrm{g} / 100 \mathrm{~g}$ of total fatty acids) of total lipids of lymph of rats*, $6 \mathrm{~h}$ after intubation

(Mean values and standard deviations)

\begin{tabular}{|c|c|c|c|c|c|c|}
\hline & \multicolumn{2}{|c|}{$\mathrm{TAG}_{n-3}$} & \multicolumn{2}{|c|}{$\mathrm{TAG}_{n-3}+\mathrm{PL}_{\mathrm{veg}}$} & \multicolumn{2}{|c|}{$\mathrm{TAG}_{\mathrm{veg}}+\mathrm{PL}_{n-3}$} \\
\hline & Mean & SD & Mean & SD & Mean & SD \\
\hline$\Sigma$ SFA & $27 \cdot 4^{\mathrm{a}}$ & 1.5 & $26 \cdot 4^{\mathrm{a}}$ & 1.0 & $26 \cdot 3^{a}$ & $1 \cdot 6$ \\
\hline $16: 0$ & $17 \cdot 8^{\mathrm{a}}$ & 1.0 & $18 \cdot 5^{a}$ & 0.7 & $17 \cdot 9^{\mathrm{a}}$ & 1.0 \\
\hline $18: 0$ & $4 \cdot 8^{a}$ & 0.4 & $5 \cdot 1^{a}$ & 0.8 & $5 \cdot 0^{\mathrm{a}}$ & 0.3 \\
\hline$\Sigma$ MUFA & $49 \cdot 9^{a}$ & 3.5 & $52 \cdot 4^{a}$ & $3 \cdot 1$ & $52 \cdot 5^{a}$ & 3.8 \\
\hline $18: 1 n-9$ & $45 \cdot 5^{\mathrm{a}}$ & 4.6 & $48.0^{\mathrm{a}}$ & 3.5 & $48 \cdot 8^{\mathrm{a}}$ & $4 \cdot 3$ \\
\hline$\Sigma$ PUFA & $22 \cdot 8^{a}$ & $2 \cdot 8$ & $21 \cdot 2^{\mathrm{a}}$ & $2 \cdot 1$ & $21 \cdot 3^{a}$ & 3.0 \\
\hline$\Sigma n-6$ PUFA & $18 \cdot 8^{a}$ & 2.6 & $17 \cdot 3^{\mathrm{a}}$ & $2 \cdot 0$ & $17 \cdot 5^{\mathrm{a}}$ & 2.5 \\
\hline $18: 2 n-6$ & $14 \cdot 2^{\mathrm{a}}$ & $2 \cdot 0$ & $12 \cdot 7^{a}$ & 1.3 & $13 \cdot 5^{a}$ & $2 \cdot 0$ \\
\hline $20: 4 n-6$ & $3 \cdot 8^{a}$ & 0.7 & $3 \cdot 8^{a}$ & 0.9 & $3.5^{\mathrm{a}}$ & 0.7 \\
\hline$\Sigma n-3$ PUFA & $3.9^{\mathrm{a}}$ & 0.2 & $3.8^{\mathrm{a}}$ & 0.1 & $3.7^{\mathrm{a}}$ & 0.9 \\
\hline $18: 3 n-3$ & $1 \cdot 1^{\mathrm{a}}$ & 0.1 & $0.7^{b}$ & 0.1 & $1.0^{\mathrm{a}}$ & 0.2 \\
\hline $20: 5 n-3$ & $0.5^{\mathrm{a}}$ & 0.0 & $0.6^{\mathrm{a}}$ & 0.0 & $0.5^{\mathrm{a}}$ & 0.2 \\
\hline $22: 6 n-3$ & $1 \cdot 8^{\mathrm{a}}$ & 0.1 & $2 \cdot 0^{\mathrm{a}}$ & 0.2 & $1.9^{\mathrm{a}}$ & 0.7 \\
\hline$n-6: n-3$ & $4 \cdot 8^{\mathrm{a}}$ & 0.5 & $4 \cdot 5^{\mathrm{a}}$ & 0.5 & $5 \cdot 0^{\mathrm{a}}$ & $1 \cdot 2$ \\
\hline Total fatty acids $(\mathrm{mg} / \mathrm{ml})$ & $13 \cdot 9^{\mathrm{a}}$ & 4.0 & $15 \cdot 5^{\mathrm{a}}$ & $9 \cdot 1$ & $15 \cdot 3^{a}$ & $5 \cdot 6$ \\
\hline
\end{tabular}

PL, phospholipids; $T_{A G}$, oil phase with $n-3 \mathrm{LC}$ PUFA esterified in $T A G ; \mathrm{TAG}_{n-3}+\mathrm{PL}_{\mathrm{veg}}$, oil and soya lecithin mix with $n-3 \mathrm{LC} P U F A$ esterified in $T A G ; T A G_{v e g}+P L_{n-3}$, oil and marine $P L$ mix with $n-3$ LC PUFA esterified in PL.

a,b Mean values within a row with unlike superscript letters are significantly different $(P<0.05$; ANOVA followed by Tukey's post hoc test).

${ }^{*} n 6$.

Table 3. Effect of the molecular carrier form of $n$-3 long-chain (LC) PUFA on fatty acid composition ( $\mathrm{g} / 100 \mathrm{~g}$ of total fatty acids) of TAG and phospholipids (PL) of lymph of rats* $6 \mathrm{~h}$ after intubation (Mean values and standard deviations)

\begin{tabular}{|c|c|c|c|c|c|c|c|c|c|c|c|c|}
\hline & \multicolumn{6}{|c|}{ Lymph TAG } & \multicolumn{6}{|c|}{ Lymph PL } \\
\hline & \multicolumn{2}{|c|}{$\mathrm{TAG}_{n-3}$} & \multicolumn{2}{|c|}{$\mathrm{TAG}_{n-3}+\mathrm{PL}_{\mathrm{veg}}$} & \multicolumn{2}{|c|}{$\mathrm{TAG}_{\mathrm{veg}}+\mathrm{PL}_{n-3}$} & \multicolumn{2}{|c|}{$\mathrm{TAG}_{n-3}$} & \multicolumn{2}{|c|}{$\mathrm{TAG}_{n-3}+\mathrm{PL}_{\mathrm{veg}}$} & \multicolumn{2}{|c|}{$\mathrm{TAG}_{\mathrm{veg}}+\mathrm{PL}_{n-3}$} \\
\hline & Mean & SD & Mean & SD & Mean & SD & Mean & SD & Mean & SD & Mean & SD \\
\hline$\Sigma$ SFA & $26 \cdot 3^{\mathrm{a}}$ & $2 \cdot 1$ & $25 \cdot 9^{\mathrm{a}}$ & 1.9 & $25 \cdot 7^{a}$ & 1.9 & $39.5^{\mathrm{a}}$ & $1 \cdot 1$ & $38.4^{\mathrm{a}}$ & 1.2 & $39 \cdot 2^{\mathrm{a}}$ & 1.3 \\
\hline $16: 0$ & $17 \cdot 8^{\mathrm{a}}$ & 1.0 & $18 \cdot 4^{\mathrm{a}}$ & 0.9 & $17 \cdot 7^{\mathrm{a}}$ & 1.0 & $20 \cdot 4^{\mathrm{a}}$ & 1.2 & $18 \cdot 8^{\mathrm{b}}$ & 0.8 & $19 \cdot 9^{a, b}$ & 1.2 \\
\hline $18: 0$ & $4 \cdot 0^{\mathrm{a}}$ & 0.4 & $4.1^{\mathrm{a}}$ & 0.5 & $4 \cdot 0^{\mathrm{a}}$ & 0.3 & $17 \cdot 6^{\mathrm{a}}$ & $1 \cdot 1$ & $18 \cdot 3^{\mathrm{a}}$ & 1.3 & $17 \cdot 8^{\mathrm{a}}$ & $1 \cdot 1$ \\
\hline$\Sigma$ MUFA & $53 \cdot 6^{a}$ & $2 \cdot 9$ & $55 \cdot 7^{a}$ & $3 \cdot 4$ & $55 \cdot 9^{a}$ & $3 \cdot 8$ & $13 \cdot 7^{a}$ & $2 \cdot 6$ & $13 \cdot 4^{a}$ & 1.9 & $14 \cdot 5^{a}$ & $3 \cdot 2$ \\
\hline $18: 1 n-9$ & $49 \cdot 0^{a}$ & $4 \cdot 1$ & $51 \cdot 3^{a}$ & $3 \cdot 8$ & $52 \cdot 3^{a}$ & 4.0 & $9 \cdot 1^{a}$ & $2 \cdot 8$ & $8 \cdot 7^{a}$ & $2 \cdot 0$ & $8 \cdot 7^{a}$ & 3.5 \\
\hline$\Sigma$ PUFA & $20 \cdot 1^{a}$ & $2 \cdot 8$ & $18 \cdot 4^{\mathrm{a}}$ & $1 \cdot 7$ & $18 \cdot 6^{a}$ & $2 \cdot 1$ & $46 \cdot 9^{a}$ & $2 \cdot 0$ & $48 \cdot 2^{\mathrm{a}}$ & $2 \cdot 5$ & $46 \cdot 3^{a}$ & 2.4 \\
\hline$\Sigma n-6$ PUFA & $16 \cdot 2^{\mathrm{a}}$ & $2 \cdot 4$ & $14 \cdot 6^{\mathrm{a}}$ & 1.7 & $14 \cdot 9^{\mathrm{a}}$ & 1.6 & $43 \cdot 7^{\mathrm{a}}$ & $2 \cdot 2$ & $44 \cdot 8^{\mathrm{a}}$ & $2 \cdot 4$ & $42 \cdot 3^{\mathrm{a}}$ & $2 \cdot 1$ \\
\hline $18: 2 n-6$ & $13 \cdot 2^{\mathrm{a}}$ & $2 \cdot 1$ & $11 \cdot 7^{\mathrm{a}}$ & 1.4 & $12 \cdot 5^{\mathrm{a}}$ & 1.5 & $23 \cdot 9^{a}$ & 2.0 & $24 \cdot 6^{\mathrm{a}}$ & $1 \cdot 7$ & $24 \cdot 2^{\mathrm{a}}$ & $2 \cdot 3$ \\
\hline $20: 4 n-6$ & $2 \cdot 3^{\mathrm{a}}$ & 0.4 & $2 \cdot 3^{\mathrm{a}}$ & 0.6 & $2 \cdot 0^{\mathrm{a}}$ & 0.4 & $18 \cdot 2^{\mathrm{a}}$ & 1.5 & $18 \cdot 8^{\mathrm{a}}$ & $2 \cdot 3$ & $16 \cdot 9^{a}$ & 1.9 \\
\hline$\Sigma n-3$ PUFA & $3 \cdot 8^{\mathrm{a}}$ & 0.4 & $3 \cdot 7^{\mathrm{a}}$ & 0.1 & $3 \cdot 5^{\mathrm{a}}$ & 0.9 & $3 \cdot 1^{\mathrm{a}}$ & 0.2 & $3 \cdot 3^{a}$ & 0.2 & $3 \cdot 9^{a}$ & $1 \cdot 1$ \\
\hline $18: 3 n-3$ & $1 \cdot 1^{\mathrm{a}}$ & 0.2 & $0.7^{b}$ & 0.1 & $1.0^{\mathrm{a}}$ & 0.1 & $0.3^{a}$ & 0.0 & $0.3^{b}$ & 0.0 & $0.3^{a}$ & 0.0 \\
\hline $20: 5 n-3$ & $0.5^{\mathrm{a}}$ & 0.1 & $0.6^{\mathrm{a}}$ & 0.0 & $0.4^{a}$ & 0.1 & $0.8^{\mathrm{a}}$ & $0 \cdot 1$ & $1.0^{\mathrm{a}}$ & 0.2 & $1 \cdot 1^{\mathrm{a}}$ & 0.4 \\
\hline $22: 6 n-3$ & $1.7^{\mathrm{a}}$ & 0.2 & $1.9^{a}$ & 0.2 & $1 \cdot 8^{\mathrm{a}}$ & 0.7 & $1.6^{a}$ & 0.2 & $1.7^{\mathrm{a}}$ & 0.3 & $2 \cdot 1^{\mathrm{a}}$ & 0.6 \\
\hline$n-6: n-3$ & $4 \cdot 2^{a}$ & 0.2 & $4 \cdot 0^{\mathrm{a}}$ & 0.5 & $4 \cdot 5^{\mathrm{a}}$ & $1 \cdot 1$ & $14 \cdot 2^{a}$ & 1.7 & $13 \cdot 5^{\mathrm{a}}$ & 0.3 & $11 \cdot 5^{a}$ & $3 \cdot 4$ \\
\hline Total fatty acids $(\mathrm{mg} / \mathrm{ml})$ & $9 \cdot 1^{a}$ & 2.5 & $12 \cdot 2^{\mathrm{a}}$ & $7 \cdot 7$ & $10 \cdot 4^{\mathrm{a}}$ & 4.9 & $1 \cdot 2^{\mathrm{a}}$ & 0.4 & $1 \cdot 1^{\mathrm{a}}$ & 0.6 & $1 \cdot 1^{\mathrm{a}}$ & 0.5 \\
\hline
\end{tabular}

$\mathrm{TAG}_{n-3}$, oil phase with $n-3 \mathrm{LC}$ PUFA esterified in TAG; $\mathrm{TAG}_{n-3}+\mathrm{PL}_{\mathrm{veg}}$, oil and soya lecithin mix with $n-3 \mathrm{LC}$ PUFA esterified in TAG; TAG $\mathrm{veg}+\mathrm{PL}_{n-3}$, oil and marine PL mix with $n-3 \mathrm{LC}$ PUFA esterified in PL.

a,b Mean values within a row with unlike superscript letters are significantly different $(P<0.05$; ANOVA followed by Tukey's post hoc test).

${ }^{*} n 6$.

form of intake $\left(\mathrm{TAG}_{n-3}\right.$ and $\left.\mathrm{TAG}_{n-3}+\mathrm{PL}_{\mathrm{veg}}\right)$. These data agree with a previous study where the proportions of $n-3$ LC PUFA in CM-PL were increased with marine PL compared with fish oil ${ }^{(23,32)}$. It has been suggested that FA absorption could be lower in anaesthetised rats than in conscious animals. Nonetheless, the relative distribution of DHA in lymph lipid fractions is expected to be similar regardless of the consciousness state of the rats ${ }^{(44)}$.

The analysis of the glyceride structure of TAG clearly showed that the molecular $n-3$ LC PUFA carrier influenced the mechanisms involved in the re-synthesis of lymph lipids. In the enterocyte, lymph TAG are mainly synthesised by the 2-MG pathway. We found that marine TAG intake $\left(\mathrm{TAG}_{n-3}\right.$ and $\mathrm{TAG}_{n-3}+\mathrm{PL}_{\mathrm{veg}}$ ) led to an equimolar distribution of DHA in the three positions (33\% of each) of lymph TAG, whereas the DHA provided was $56 \%$ esterified in the $s n-2$ position in marine TAG formulation. This showed that the $s n-2$ position of the dietary TAG was not fully conserved in lymph TAG. A similar conclusion was drawn when structured TAG rich in $\alpha$-linolenic acid (18 : $3 n-3)$ were used, that is, only $50 \%$ of $\alpha$-linolenic acid located in the $s n-2$ position of dietary TAG were recovered at this position in rat lymph $\mathrm{TAG}^{(45)}$. This was interpreted as either (i) an isomerisation of 2-MG into 1-MG prior to the lipolytic activity of pancreatic lipase ${ }^{(46)}$ or (ii) a hydrolysis of the absorbed $2-\mathrm{MG}$ by an intestinal lipase in the enterocyte ${ }^{(47)}$. This suggested 
Table 4. Effect of the molecular carrier form of $n-3$ long-chain (LC) PUFA on fatty acid distribution (\% esterified in the internal sn-2 position) in TAG and phospholipids (PL) of lymph of rats*, $6 \mathrm{~h}$ after intubation

(Mean values and standard deviations)

\begin{tabular}{|c|c|c|c|c|c|c|c|c|c|c|c|c|}
\hline & \multicolumn{6}{|c|}{ Lymph TAG } & \multicolumn{6}{|c|}{ Lymph PL } \\
\hline & \multicolumn{2}{|c|}{$\mathrm{TAG}_{n-3}$} & \multicolumn{2}{|c|}{$\mathrm{TAG}_{n-3}+\mathrm{PL}_{\mathrm{veg}}$} & \multicolumn{2}{|c|}{$\mathrm{TAG}_{\mathrm{veg}}+\mathrm{PL}_{n-3}$} & \multicolumn{2}{|c|}{$\mathrm{TAG}_{n-3}$} & \multicolumn{2}{|c|}{$\mathrm{TAG}_{n-3}+\mathrm{PL}_{\mathrm{veg}}$} & \multicolumn{2}{|c|}{$\mathrm{TAG}_{\mathrm{veg}}+\mathrm{PL}_{n-3}$} \\
\hline & Mean & SD & Mean & SD & Mean & SD & Mean & SD & Mean & SD & Mean & SD \\
\hline$\Sigma$ SFA & 31.6 & $9 \cdot 6$ & $27 \cdot 2^{\mathrm{a}}$ & 1.4 & $28 \cdot 8^{\mathrm{a}}$ & 3.4 & $20 \cdot 6^{a}$ & 8.3 & $17 \cdot 6^{a}$ & $10 \cdot 1$ & $13 \cdot 7^{a}$ & 3.6 \\
\hline $16: 0$ & $29 \cdot 2^{a}$ & $6 \cdot 8$ & $29 \cdot 1^{a}$ & 1.0 & $29 \cdot 5^{a}$ & $2 \cdot 1$ & $22 \cdot 3^{a}$ & 8.6 & $20 \cdot 0^{a}$ & $11 \cdot 1$ & $14 \cdot 7^{a}$ & 3.8 \\
\hline $18: 0$ & $28 \cdot 6^{a}$ & $5 \cdot 8$ & $22 \cdot 7^{\mathrm{a}}$ & $1 \cdot 3$ & $23 \cdot 2^{a}$ & 3.7 & $17 \cdot 4^{\mathrm{a}}$ & 8.4 & $14 \cdot 7^{\mathrm{a}}$ & 9.6 & $10 \cdot 9^{a}$ & 3.4 \\
\hline$\Sigma$ MUFA & $32 \cdot 2^{\mathrm{a}}$ & $3 \cdot 3$ & $34 \cdot 0^{\mathrm{a}}$ & 0.9 & $33 \cdot 5^{a}$ & $1 \cdot 2$ & $38 \cdot 2^{a}$ & 9.7 & $39 \cdot 0^{a}$ & 4.9 & $35 \cdot 7^{a}$ & $8 \cdot 3$ \\
\hline $18: 1 n-9$ & $33 \cdot 2^{\mathrm{a}}$ & $3 \cdot 4$ & $35 \cdot 0^{a}$ & 0.6 & $34 \cdot 1^{a}$ & 0.9 & $43 \cdot 1^{a}$ & $7 \cdot 6$ & $46 \cdot 4^{a}$ & 4.5 & $46 \cdot 8^{a}$ & 8.4 \\
\hline$\Sigma$ PUFA & $39 \cdot 0^{a}$ & 4.6 & $39 \cdot 9^{a}$ & 1.6 & $39 \cdot 2^{\mathrm{a}}$ & 1.5 & $78 \cdot 6^{a}$ & 8.5 & $79 \cdot 1^{a}$ & $9 \cdot 2$ & $85 \cdot 7^{a}$ & $5 \cdot 7$ \\
\hline$\sum n-6$ PUFA & $41 \cdot 0^{\mathrm{a}}$ & 4.4 & $42 \cdot 0^{a}$ & 1.7 & $43 \cdot 1^{a}$ & 0.9 & $79 \cdot 3^{a}$ & 9.3 & $79 \cdot 6^{a}$ & $9 \cdot 1$ & $86 \cdot 7^{a}$ & $6 \cdot 4$ \\
\hline $18: 2 n-6$ & $44 \cdot 3^{a}$ & $5 \cdot 0$ & $43 \cdot 9^{a}$ & $2 \cdot 0$ & $44 \cdot 9^{a}$ & 1.4 & $80 \cdot 3^{a}$ & 5.5 & $79 \cdot 3^{a}$ & $7 \cdot 7$ & $87.4^{\mathrm{a}}$ & $7 \cdot 4$ \\
\hline $20: 4 n-6$ & $28 \cdot 6^{a}$ & 4.4 & $34 \cdot 3^{b}$ & $2 \cdot 3$ & $32 \cdot 1^{a, b}$ & $1 \cdot 1$ & $79 \cdot 8^{a}$ & $6 \cdot 3$ & $81 \cdot 8^{a}$ & $11 \cdot 6$ & $87 \cdot 6^{a}$ & $6 \cdot 4$ \\
\hline$\Sigma n-3$ PUFA & $30 \cdot 3^{a}$ & $6 \cdot 0$ & $32 \cdot 3^{a}$ & 1.5 & $23.9^{b}$ & $2 \cdot 4$ & $73 \cdot 1^{\mathrm{a}}$ & $11 \cdot 1$ & $73 \cdot 4^{a}$ & $12 \cdot 0$ & $77 \cdot 0^{\mathrm{a}}$ & $13 \cdot 7$ \\
\hline $18: 3 n-3$ & $31 \cdot 2^{\mathrm{a}}$ & 4.0 & $27 \cdot 9^{a}$ & 1.4 & $31.4^{a}$ & $1 \cdot 1$ & $59 \cdot 9^{a, b}$ & $6 \cdot 1$ & $53 \cdot 1^{a}$ & $5 \cdot 1$ & $63 \cdot 5^{\mathrm{b}}$ & $7 \cdot 2$ \\
\hline $20: 5 n-3$ & $18 \cdot 2^{\mathrm{a}, \mathrm{b}}$ & 3.5 & $19 \cdot 4^{\mathrm{a}}$ & $2 \cdot 0$ & $14.5^{\mathrm{b}}$ & 3.6 & $75 \cdot 1^{\mathrm{a}}$ & $7 \cdot 3$ & $83 \cdot 5^{\mathrm{a}}$ & $19 \cdot 1$ & $85 \cdot 6^{a}$ & 11.7 \\
\hline $22: 6 n-3$ & $30 \cdot 4^{a}$ & 8.5 & $33 \cdot 7^{a}$ & $1 \cdot 7$ & $17 \cdot 3^{b}$ & 1.5 & $72 \cdot 1^{a}$ & $5 \cdot 1$ & $73 \cdot 7^{a}$ & $10 \cdot 6$ & $78 \cdot 4^{a}$ & $19 \cdot 7$ \\
\hline
\end{tabular}

$\mathrm{TAG}_{n-3}$, oil phase with $n-3 \mathrm{LC}$ PUFA esterified in TAG; $\mathrm{TAG}_{n-3}+\mathrm{PL}_{\mathrm{veg}}$, oil and soya lecithin mix with $n-3 \mathrm{LC}$ PUFA esterified in TAG; TAG $\mathrm{veg}+\mathrm{PL} \mathrm{L}_{n-3}$, oil and marine PL mix with $n-3 \mathrm{LC}$ PUFA esterified in PL.

a,b Mean values within a row with unlike superscript letters are significantly different $(P<0.05$; ANOVA followed by Tukey's post hoc test). ${ }^{*} n 6$.

that new metabolic pathways could take place as soon as the concentration of a lipid species varied greatly, thus ensuring a 'homeostatic' state. On the contrary, in marine PL, DHA was exclusively ( $>74 \%$ ) esterified in the $s n-2$ position of the glycerol backbone. After PL digestion, DHA was mainly released as NEFA, due to a predominant activity of $\mathrm{PLA}_{2}$, specific of the $s n-2$ position of $\mathrm{PL}^{(48)}$. Thus, the presence of DHA in the $s n-2$ position of lymph TAG suggested that the glycerol-3-phosphate pathway was involved for the de novo TAG synthesis using unesterified DHA. Indeed, the glycerol-3-phosphate pathway could account for at least $15 \%$ of lymph TAG synthesis. Nevertheless, the major pathway for re-synthesis of lymph TAG seemed to be the 2-MG pathway, leading to the incorporation of a large part of free DHA on the 2-MG backbone. In this way, $\mathrm{TAG}_{\mathrm{veg}}+\mathrm{PL}_{n-3}$ ensured a DHA enrichment in the $s n-1 / 3$ positions of lymph TAG compared with the marine TAG groups $\left(\mathrm{TAG}_{n-3}\right.$ and $\mathrm{TAG}_{n-3}+\mathrm{PL}_{\mathrm{veg}}$ ). The analysis of the glyceride structure of PL showed the same $n-3$ LC PUFA repartition in the three dietary groups. Lymph PL mainly originate from the re-acylation of 1-lysophospholipids; this suggested that, irrespective of the amount of free DHA in the enterocyte, the composition of lymph $\mathrm{PL}$ is highly regulated with an incorporation mainly in the $s n-2$ position.

These mechanisms are confirmed with the metabolic fate of EPA. Indeed, EPA was less esterified in the $s n-2$ position of lymph TAG when provided as marine PL than as marine TAG. Nevertheless, since EPA was mainly distributed in the $s n-1 / 3$ positions of marine TAG and in $s n-2$ position of marine PL, it was essentially absorbed as NEFA after gastro-intestinal hydrolysis. Free EPA was then incorporated either in the $s n-1 / 3$ positions of lymph TAG or in the $s n-2$ position of lymph PL.

In conclusion, the present study was undertaken to analyse the impact of different molecular carriers of $n-3$ LC PUFA that could increase their bioavailability, based on in vivo data. Our results showed that dietary PL from vegetable or animal sources added to the oily formulations, at the ratio of $10 \%$, did not increase lipid absorption. Although lipolysis differed according to the composition of the formulation, it seemed that the molecular carrier did not greatly modify the intestinal absorption of $n-3$ LC PUFA. In contrast, the nature of the dietary lipids might modulate FA incorporation and distribution in lymph lipid fractions. However, it would be interesting to complete the present study with the analysis of gene and protein expressions as well as with the activities of some enzymes implied in the intracellular lipid metabolism pathways to consolidate our data. The fact that, when provided as marine PL, DHA was better incorporated in lymph PL and was externalised in lymph TAG may further affect its metabolic fate and tissue accretion. Indeed, previous reports indicated that using PL as $n-3$ LC PUFA carriers can be more efficient than TAG regarding the metabolisation and hypoadipogenic effect of EPA and DHA ${ }^{(10,15,16,49-51)}$.

\section{Supplementary material}

For supplementary material/s referred to in this article, please visit https://doi.org/10.1017/S0007114519001491

\section{Acknowledgements}

Authors are grateful to Novastell and in particular Thierry Coste (Novastel) for providing Lecimarin F50, and also to Polaris for supplying fish oils. The authors also wish to thank Axelle Grélard from Bordeaux University, CNRS, CBMN-UMR 5248, for RMN analysis.

The study was partly financially supported by the French National Association for Research and Technology (ANRT, no. 2015/1182).

None of the authors has any conflicts of interest to declare. 


\section{References}

1. Riediger ND, Othman RA, Suh M, et al. (2009) A systemic review of the roles of $n-3$ fatty acids in health and disease. J Am Diet Assoc 109, 668-679.

2. Dyall SC \& Michael-Titus AT (2008) Neurological benefits of omega-3 fatty acids. NeuroMolecular Med 10, 219-235.

3. Calder PC (2017) Omega-3 fatty acids and inflammatory processes: from molecules to man. Biochem Soc Trans $\mathbf{4 5}$, $1105-1115$.

4. Saini RK \& Keum Y-S (2018) Omega-3 and omega-6 polyunsaturated fatty acids: dietary sources, metabolism, and significance - a review. Life Sci 203, 255-267.

5. Simopoulos AP (2016) An increase in the omega-6/omega-3 fatty acid ratio increases the risk for obesity. Nutrients $\mathbf{8}$, $128-145$.

6. Zarate R, el Jaber-Vazdekis N, Tejera N, et al. (2017) Significance of long chain polyunsaturated fatty acids in human health. Clin Transl Med 6, 25-44.

7. Dubuisson C, Carrillo S, Dufour A, et al. (2017) The French dietary survey on the general population (INCA3) - French Agency on Food, Environmental and Occupational Health and Safety (ANSES). Parma: European Food Safety Authority.

8. Astorg P-O, Bougnoux P, Calvarin J, et al. (2011) Actualisation des apports nutritionnels conseillés pour les acides gras Version intégrant les modifications apportés par l'erratum du 28 juillet 2011 (Update of Recommended nutritional intake for fatty acids - Version integrating the modifications brought by the erratum of 28 July 2011).

9. Mortureux M (2017) Avis et rapport de l'Anses sur la troisième étude individuelle nationale des consommations alimentaires INCA 3 (ANSES Opinion and Report on the Third National Individual Survey of Food Consumption - INCA 3). Paris: ANSES.

10. Cansell M (2010) Marine phospholipids as dietary carriers of long-chain polyunsaturated fatty acids. Lipid Technol $\mathbf{2 2}$, 223-226.

11. Couëdelo L, Amara S, Lecomte M, et al. (2015) Impact of various emulsifiers on ALA bioavailability and chylomicron synthesis through changes in gastrointestinal lipolysis. Food Funct 6 1726-1735.

12. Couëdelo L, Boué-Vaysse C, Fonseca L, et al. (2011) Lymphatic absorption of $\alpha$-linolenic acid in rats fed flaxseed oil-based emulsion. Br J Nutr 105, 1026-1035.

13. Garaiova I, Guschina IA, Plummer SF, et al. (2007) A randomised cross-over trial in healthy adults indicating improved absorption of omega-3 fatty acids by pre-emulsification. Nutr J 6, 4-13.

14. Michalski MC, Genot C, Gayet C, et al. (2013) Multiscale structures of lipids in foods as parameters affecting fatty acid bioavailability and lipid metabolism. Prog Lipid Res 52, 354-373.

15. Graf BA, Duchateau GSMJE, Patterson AB, et al. (2010) Age dependent incorporation of 14C-DHA into rat brain and body tissues after dosing various 14C-DHA-esters. Prostaglandins Leukot Essent Fatty Acids 83, 89-96.

16. Rossmeisl M, Jilkova ZM, Kuda O, et al. (2012) Metabolic effects of $n-3$ PUFA as phospholipids are superior to triglycerides in mice fed a high-fat diet: possible role of endocannabinoids. PLOS ONE 7, e38834.

17. Song JH, Fujimoto K \& Miyazawa T (2000) Polyunsaturated $(n-3)$ fatty acids susceptible to peroxidation are increased in plasma and tissue lipids of rats fed docosahexaenoic acidcontaining oils. J Nutr 130, 3028-3033.

18. Song JH \& Miyazawa T (2001) Enhanced level of $n-3$ fatty acid in membrane phospholipids induces lipid peroxidation in rats fed dietary docosahexaenoic acid oil. Atherosclerosis 155 9-18.
19. Ramprasath VR, Eyal I, Zchut S, et al. (2013) Enhanced increase of omega-3 index in healthy individuals with response to 4-week $n$-3 fatty acid supplementation from krill oil versus fish oil. Lipids Health Dis 12, 178-199.

20. Yurko-Mauro K, Kralovec J, Bailey-Hall E, et al. (2015) Similar eicosapentaenoic acid and docosahexaenoic acid plasma levels achieved with fish oil or krill oil in a randomized double-blind four-week bioavailability study. Lipids Health Dis 14, 99-108.

21. Castro-Gómez MP, Holgado F, Rodríguez-Alcalá LM, et al. (2015) Comprehensive study of the lipid classes of krill oil by fractionation and identification of triacylglycerols, diacylglycerols, and phospholipid molecular species by using UPLC/QToF-MS. Food Anal Methods 8, 2568-2580.

22. European Food Safety Authority (EFSA) (2009) Safety of 'lipid extract from Euphausia superba' as a novel food ingredient. EFSA J 7, 938.

23. Cansell M, Nacka F \& Combe N (2003) Marine lipid-based liposomes increase in vivo FA bioavailability. Lipids 38, 551-559.

24. Bollman JL, Cain JC \& Grindlay JH (1948) Techniques for the collection of lymph from the liver, small intestine, or thoracic duct of the rat. J Lab Clin Med 33, 1349-1352.

25. Cansell M, Bardeau T, Morvan E, et al. (2017) Phospholipid profiles of oleaginous pressed cakes using NMR and gas chromatography. J Am Oil Chem Soc 94, 1219-1223.

26. Folch J, Lees M \& Sloane Stanley GH (1957) A simple method for the isolation and purification of total lipides from animal tissues. J Biol Chem 226, 497-509.

27. Castro-Gómez P, Fontecha J \& Rodríguez-Alcalá LM (2014) A high-performance direct transmethylation method for total fatty acids assessment in biological and foodstuff samples. Talanta 128, 518-523.

28. Sehl A, Couëdelo L, Fonseca L, et al. (2018) A critical assessment of transmethylation procedures for $n-3$ long-chain polyunsaturated fatty acid quantification of lipid classes. Food Chem 251, 1-8.

29. Wolff R, Combe N \& Entressangles B (1985) Positional distribution of fatty acids in cardiolipin of mitochondria from 21-dayold rats. Lipids 20, 908-914.

30. Carrière F, Renou C, Lopez V, et al. (2000) The specific activities of human digestive lipases measured from the in vivo and in vitro lipolysis of test meals. Gastroenterology 119, 949-960.

31. Minekus M, Alminger M, Alvito P, et al. (2014) A standardised static in vitro digestion method suitable for food - an international consensus. Food Funct 5, 1113-1124.

32. Murota K, Takagi M, Watanabe Y, et al. (2018) Roe-derived phospholipid administration enhances lymphatic docosahexaenoic acid-containing phospholipid absorption in unanesthetized rats. Prostaglandins Leukot Essent Fatty Acids 139, 40-48.

33. Carriere F, Barrowman JA, Verger R, et al. (1993) Secretion and contribution to lipolysis of gastric and pancreatic lipases during a test meal in humans. Gastroenterology 105, 876-888.

34. Akanbi TO, Sinclair AJ \& Barrow CJ (2014) Pancreatic lipase selectively hydrolyses DPA over EPA and DHA due to location of double bonds in the fatty acid rather than regioselectivity. Food Chem 160, 61-66.

35. Bottino NR, Vandenburg GA \& Reiser R (1967) Resistance of certain long-chain polyunsaturated fatty acids of marine oils to pancreatic lipase hydrolysis. Lipids 2, 489-493.

36. Nishimukai M, Hara H \& Aoyama Y (2003) Enteral administration of soyabean lecithin enhanced lymphatic absorption of triacylglycerol in rats. Br J Nutr $\mathbf{9 0}, 565-571$.

37. Borgström B (1980) Importance of phospholipids, pancreatic phospholipase A2, and fatty acid for the digestion of dietary fat: in vitro experiments with the porcine enzymes. Gastroenterology 78, 954-962. 
38. Larsson A \& Erlanson-Albertsson C (1986) Effect of phosphatidylcholine and free fatty acids on the activity of pancreatic lipase-colipase. Biochim Biophys Acta 876, 543-550.

39. de Haas GH, Postema MM, Nieuwenhuizen W, et al. (1968) Purification and properties of phospholipase A and its zymogen from porcine pancreas. Bull Soc Chim Biol (Paris) 159, 118-129.

40. Jain MK \& Rogers J (1989) Substrate specificity for interfacial catalysis by phospholipase A2 in the scooting mode. Biochim Biophys Acta 1003, 91-97.

41. Ghomashchi F, Yu BZ, Berg O, et al. (1991) Interfacial catalysis by phospholipase A2: substrate specificity in vesicles. Biochemistry 30, 7318-7329.

42. Singer AG, Ghomashchi F, Le Calvez C, et al. (2002) Interfacial kinetic and binding properties of the complete set of human and mouse groups I, II, V, X, and XII secreted phospholipases A2. J Biol Chem 277, 48535-48549.

43. Bahnson BJ (2005) Structure, function and interfacial allosterism in phospholipase A2: insight from the anion-assisted dimer. Arch Biochem Biophys 433, 96-106.

44. Subbaiah PV, Dammanahalli KJ, Yang P, et al. (2016) Enhanced incorporation of dietary DHA into lymph phospholipids by altering its molecular carrier. Biochim Biophys Acta 1861, 723-729.

45. Couëdelo L, Vaysse C, Vaique E, et al. (2012) The fraction of $\alpha$-linolenic acid present in the $s n-2$ position of structured triacylglycerols decreases in lymph chylomicrons and plasma triacylglycerols during the course of lipid absorption in rats. J Nutr 142, 70-75.

46. Mattson FH \& Volpenhein RA (1964) The digestion and absorption of triglycerides. J Biol Chem 239, 2772-2777.

47. Chon S-H, Zhou YX, Dixon JL, et al. (2007) Intestinal monoacylglycerol metabolism: developmental and nutritional regulation of monoacylglycerol lipase and monoacylglycerol acyltransferase. J Biol Chem 282, 33346-33357.

48. Cohn JS, Wat E, Kamili A, et al. (2008) Dietary phospholipids, hepatic lipid metabolism and cardiovascular disease. Curr Opin Lipidol 19, 257-262.

49. Awada M, Meynier A, Soulage CO, et al. (2013)n-3 PUFA added to high-fat diets affect differently adiposity and inflammation when carried by phospholipids or triacylglycerols in mice. Nutr Metab 10, 23-37.

50. Valenzuela A, Valenzuela V, Sanhueza J, et al. (2005) Effect of supplementation with docosahexaenoic acid ethyl ester and $s n-2$ docosahexaenyl monoacylglyceride on plasma and erythrocyte fatty acids in rats. Ann Nutr Metab 49 , 49-53.

51. Destaillats F, Oliveira M, Bastic Schmid V, et al. (2018) Comparison of the incorporation of DHA in circulatory and neural tissue when provided as triacylglycerol (TAG), monoacylglycerol (MAG) or phospholipids (PL) provides new insight into fatty acid bioavailability. Nutrients $\mathbf{1 0}$, 620-632. 